\title{
Apresentação
}

\section{EDUCAÇÃO INTEGRAL: TENSÕES E DESDOBRAMENTOS DE EXPERIÊNCIAS EDUCATIVAS CONTEMPORÂNEAS}

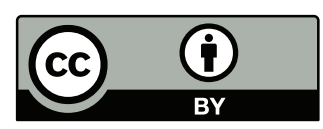

Educação: Teoria e Prática, Rio Claro, SP, Brasil - eISSN: 1981-8106

Está licenciada sob Licença Creative Common

Este número temático proposto para a revista Educação: Teoria e Prática decorre de pesquisa interinstitucional desenvolvida com o apoio da Capes e coordenada pelos professores doutores Debora Jeffrey (Unicamp), Antonio Carlos Maciel (UNIR) e Maria Lília Imbiriba Sousa Colares (Ufopa), e seu eixo principal foi a análise em vários “acordes" de programas de educação integral. A este tema de pesquisa somaram-se reflexões decorrentes de análises relativas a programas de educação em tempo integral na região Amazônica, no estado de São Paulo e em Portugal, além de entrevista com o pesquisador Romualdo Portela de Oliveira, que vem analisando as desigualdades educacionais, aspecto acionado pelos discursos governamentais para a proposição do aumento do tempo das jornadas escolares.

Em resumo, a publicação aborda a diversidade e a desigualdade regionais, características do Brasil, divulgando resultados de pesquisas relativas a experiências pedagógicas, políticas e conteúdos que fundamentam a educação integral.

Nunca é demais lembrar que a região Norte, associada à região Nordeste, apresentam os piores indicadores educacionais, de modo que projetos de educação integral podem lograr êxito tanto a medida em que se consubstanciem como experiências de enriquecimento curricular e articulação entre conhecimento científico, tecnológico e culturas locais, como podem redundar no aprofundamento de históricas desigualdades. 
Dados selecionados para o início desta década (2010) indicavam que no Norte do Brasil apenas $69 \%$ das crianças de 4 e 5 anos tinham acesso aos sistemas de ensino e cerca de 200 mil estavam fora da escola ${ }^{1}$, assim como $16 \%$ dos adolescentes entre 15 e 17 anos. Em 2016, dados do censo escolar indicavam que $27,3 \%$ dos estudantes do ensino fundamental e $41,9 \%$ dos matriculados no ensino médio apresentavam distorção idade-série, indicador que atesta tanto atraso no ingresso na escola quanto dificuldades de progressão na escolaridade. ${ }^{2}$

Dados de 2013, identificados com base no Censo Escolar, apresentavam as escolas públicas de ensino fundamental dessa mesma região como menos equipadas quando comparadas a escolas localizadas em outras regiões do Brasil. A exemplo, apenas 24,5\% dessas escolas possuíam bibliotecas ou sala de leitura e somente $14 \%$ declararam oferecer aos estudantes quadra de esportes para a prática de atividades físicas. ${ }^{3}$

No caso da formação dos docentes a região Norte, ainda que tenha apresentado melhorias na formação inicial de seus professores, mantém grande parte desses profissionais sem formação no ensino superior. Em 2013, apenas 49\% dos professores em atuação na educação infantil tinham formação superior, proporção que, em 2016, sobe para 58,2\%. Já no ensino fundamental (considerados os nove anos), em 2016, 24,4\% dos professores não tinham ensino superior, enquanto no ensino médio $5 \%$ ainda se encontravam nesta situação. ${ }^{4}$

É a respeito de projetos e experiências desenvolvidas nesse contexto desconhecido para grande parte dos investigadores do Brasil e do exterior a que referem os artigos que integram esta proposta.

Mais precisamente, tratam-se de trabalhos que analisam a denominada "Educação integral" disseminada a partir do início deste século como política pública apoiada e induzida pelo Ministério da Educação (MEC) e que, a partir de 2014, configura-se como meta governamental, dada sua previsão no Plano Nacional de Educação. Nesse sentido, os artigos analisam diversas faces do Programa Mais Educação.

Analisando o Programa Mais Educação, na região Amazônica, apresentam-se os trabalhos de Gerusa Vidal Ferreira e Lília Imbiriba Sousa Colares, intitulado "Educação de tempo integral em Santarém: ações da Secretaria Municipal de Educação”, e de Clênya Ruth Alves Vasconcelos e Solange Helena Ximenes Rocha "Reflexões sobre a escola do campo

\footnotetext{
${ }^{1}$ Disponível em: <https:/goo.gl/BhZej2>. Acesso em: 27 fev. 2017.

${ }^{2}$ Disponível em: <https://goo.gl/udyJMz>. Acesso em: 27 fev. 2017.

${ }^{3}$ Disponível em: <https://goo.gl/udyJMz>. Acesso em: 27 fev. 2017.

${ }^{4}$ Disponível em: <https://goo.gl/udyJMz>. Acesso em: 9 mar. 2018.
} 
em tempo integral no município de Santarém/Pará". Os trabalhos, oriundos de pesquisas de natureza qualitativa, analisam o programa desenvolvido no âmbito do município de Santarém.

Refletindo sobre experiências de ampliação da jornada escolar no estado de São Paulo, considerando também o Programa Mais Educação em paralelo ao Programa Educação Integral proposto pelo governo paulista, o dossiê apresenta o texto de Elisangela Maria Pereira Schimonek e Teise de Oliveira Guaranha Garcia, "Programa Mais Educação e o Novo Modelo de escola de tempo integral em São Paulo: semelhanças e singularidades". O primeiro programa implantado pelo MEC em 2008 por meio de convênios com estados e municípios; e o segundo, pela Secretaria de Educação do Estado de São Paulo, em 2012. Neste trabalho, prioritariamente com base em pesquisa documental, as autoras analisam esses programas considerando: objetivos declarados, público-alvo, concepção de educação integral, a presença do setor privado, seleção das escolas, profissionais envolvidos e fontes de recursos.

Já o impacto do Programa Mais Educação, medido por avaliações em larga escala com base nos dados coletados pelo INEP, recebe tratamento no artigo de Rosana Ramos de Souza e Anselmo Alencar Colares, “A avaliação em larga escala nos centros educacionais de tempo integral: mais tempo, melhores resultados?". A análise deste trabalho recai sobre o desempenho do Centro Educacional de Tempo Integral (CETI) Deputado Gláucio Gonçalves, do Amazonas, auferido por avaliações de larga escala. O estudo pautou-se em documentos, tais como o Plano de Gestão e Regimento Geral dos CETI, e na análise de microdados disponíveis em bancos nacionais e estaduais.

A educação integral, no âmbito do ensino superior, é tema do artigo de João Ricardo Silva e Tânia Suely Azevedo Brasileiro, "Educação como prática da liberdade e a perspectiva da Educação Integral no Ensino Superior", enquanto os trabalhos de Ana Elisa Spaolonzi Queiroz Assis e Celso Mendes Ferreira da Silva, em "Educação integral, tempo e espaço: problematizando conceitos", e o ensaio de Elaine Cristina Melo Duarte e Mara Regina Martins Jacomeli, em “A Educação Integral na perspectiva histórico-crítica: para além da ampliação do tempo escolar", analisam do ponto de vista filosófico e histórico as perspectivas de educação integral em pauta.

Silva e Brasileiro, utilizando pesquisa bibliográfica e uma abordagem materialista histórica-dialética, consideram a educação integral como busca pelo "interconhecimento". A partir de publicações entre 2009 e 2012 de Em Aberto, revista do Instituto Nacional de Estudos e Pesquisas Educacionais Anísio Teixeira (INEP), Assis e Silva problematizam o conceito de educação integral e as categorias de tempo e espaço presentes naquelas publicações, revelando 
a multiplicidade conceitual "que provoca discussão sobre uma concepção crítica de educação integral". Já Jacomeli e Melo, considerando a perspectiva "marxista da pedagogia históricocrítica", concluem que esse tipo de educação em tempo integral não faz sentido, pois amplia o tempo de permanência da criança na escola, mas não garante o que proclama o discurso das políticas públicas, isto é, uma formação mais ampla e, consequente, melhoria da educação.

Finalizando os textos relacionados à experiência brasileira, este número apresenta o trabalho de Pedro Ganzeli, que toma o princípio da gestão democrática da educação como eixo para análise de políticas de "educação" integral. Neste artigo "Educação integral: direito público subjetivo", o autor busca colaborar para a construção de um "referencial conceitual sobre a educação integral", tendo em vista a formação de um sujeito de direitos.

Complementarmente, e considerando que a ampliação do tempo de permanência na escola, durante a fase de escolaridade obrigatória, não é iniciativa brasileira, o dossiê é integrado pelo texto de Selma Venco, "Tempo e educação: reflexões sobre França e Alemanha" e finalizado com o texto de Carlos Pires, da Universidade de Lisboa, "A escola a tempo inteiro em Portugal: dimensões de análise, ideias e hibridismos". Para Venco, a análise sociológica do tempo ilumina a reflexão sobre dois modelos europeus de atendimento escolar em período integral: o francês, que se mantém organizado por meio da ampliação curricular, e o alemão, que se reorganiza para responder aos resultados em testes internacionais.

Pires, por sua vez, apresenta "Escola a Tempo Inteiro", encarando-a como política pública de educação, e preconiza a emergência de novas formas de ação educativa, de outra concessão de escola pública, que monopoliza a educação integral do aluno e de outros modos de administração na prestação de serviços públicos de educação.

O número temático encerra-se com uma entrevista de Romualdo Luiz Portela de Oliveira, pesquisador na Faculdade de Educação da Universidade de São Paulo, desenvolvida por Camila Arelaro Caetano, na qual o entrevistado, atualizando o cenário das políticas em educação integral, apresenta possibilidades relativas a políticas e ações em relação à implementação de uma escola de educação integral no Brasil.

Profa. dra. Theresa Adrião Faculdade de Educação - Unicamp 